\title{
THE SUPPORT OR INDIFFERENCE OF THE RESIDENTS FOR THE DEVELOPMENT OF HERITAGE TOURISM IN THE CITY OF GIURGIU, ROMANIA
}

DOI: http://dx.doi.org/10.18509/GBP.2020.73

UDC: 338.48-6:930.85]:303.62-054.4(498)

\author{
Camelia Teodorescu ${ }^{1}$ \\ Daniel Peptenatu ${ }^{1}$ \\ Andrei Ducman ${ }^{1}$ \\ Irina-Valentina Radoi ${ }^{1}$ \\ Laurentiu Stefan Szemkovics ${ }^{1}$ \\ ${ }^{1}$ Faculty of Geography, CAIMT (Research Center for Integrated \\ Analysis and Territorial Management), University of Bucharest, Romania \\ ${ }^{2}$ National Archives of Romania, Bucharest, Romania
}

\begin{abstract}
Heritage tourism is recognized as a sustainable economic alternative. In the area of the city of Giurgiu, the medieval fortress could represent an important alternative for local development, given the economic decline in which the latter finds itself. Our study tries to determine the extent to which the success and sustainability of this type of development, based on ruin-like tourism kind or on material - archeological cultural tourism kind, depends on the support obtained from the local residents. From a methodological point of view, a questionnaire was applied among the resident population. The number of questionnaires applied was 198, including persons of different sexes, ages and professional training. The content of the questions was based on the knowledge of the residents regarding the patrimonial value of the fortress of Giurgiu, from the proximity of the dwelling and, to what extent it could come to support the heritage tourism, as an alternative to local development. The methodology used was able to give a clear explanation of the insufficient knowledge of the local history by the residents, which is in contrast to the desire to develop heritage tourism. The obtained results offer a favorable framework for supporting the local population on what concerns the historical knowledge, so that heritage tourism may become a natural phenomenon by itself. Even better documentation of the residents, as an activity supported by local authorities, could lead to the development of sustainable heritage tourism.
\end{abstract}

Keywords: heritage, tourism, monuments, residents, economy

\section{INTRODUCTION}

Concerns about finding solutions in order to raise the standard of living in areas where industry has shrunk considerably, are becoming clearer. Tourism is an alternative [9], [6], [4]. The material cultural tourism based on the ruins of the fortresses raised in the medieval period, is a viable resource [1], [12], [8]. The city of Giurgiu, of Romania, has a favorable geographical position, due to being a harbour on the Danube River and due to such ruins like those of the Fortress of Giurgiu. The ruins of this city are listed in the List of historical monuments made by the Ministry of Culture in Romania. The history of the fortress could represent the most important point of the Fortress of Giurgiu and, equally, it could represent a lesson of history and geography for students [5], [7]. Both 
archaeological- cultural- material- tourism and educational tourism offer the framework of learning through real examples [14], [11]. Historians have tried to make a clearer picture as much as possibe, of the evolution of this Danubian fortress, by linking military events, Ottoman invasions or other such events, without establishing a clear dating for the erection of this citadel [15]. What is important, however, is the repeated mention of important names in the history of Romania (of the Romanian Country), such as Mircea cel Batran or Vlad Tepes [13], [14]. Ruiniform cultural tourism, based on the traces existing in a locality, cannot be developed though, but for the acceptance and participation of the residential population. The residents are the ones who can support this economic activity. The relationship between residents and tourism is a direct one [2], [3], [16], [17], [10]. The type of tourism to be developed must be understood and promoted by those living in the vicinity of the ruiniform heritage. The promotion can be done by supporting and respecting history and what it has left for us.

\section{METHODOLOGY}

In order to carry out this study, we resorted to the simple, empirical method, in which a questionnaire was applied to a number of 198 inhabitants of the city of Giurgiu (figure $1)$.
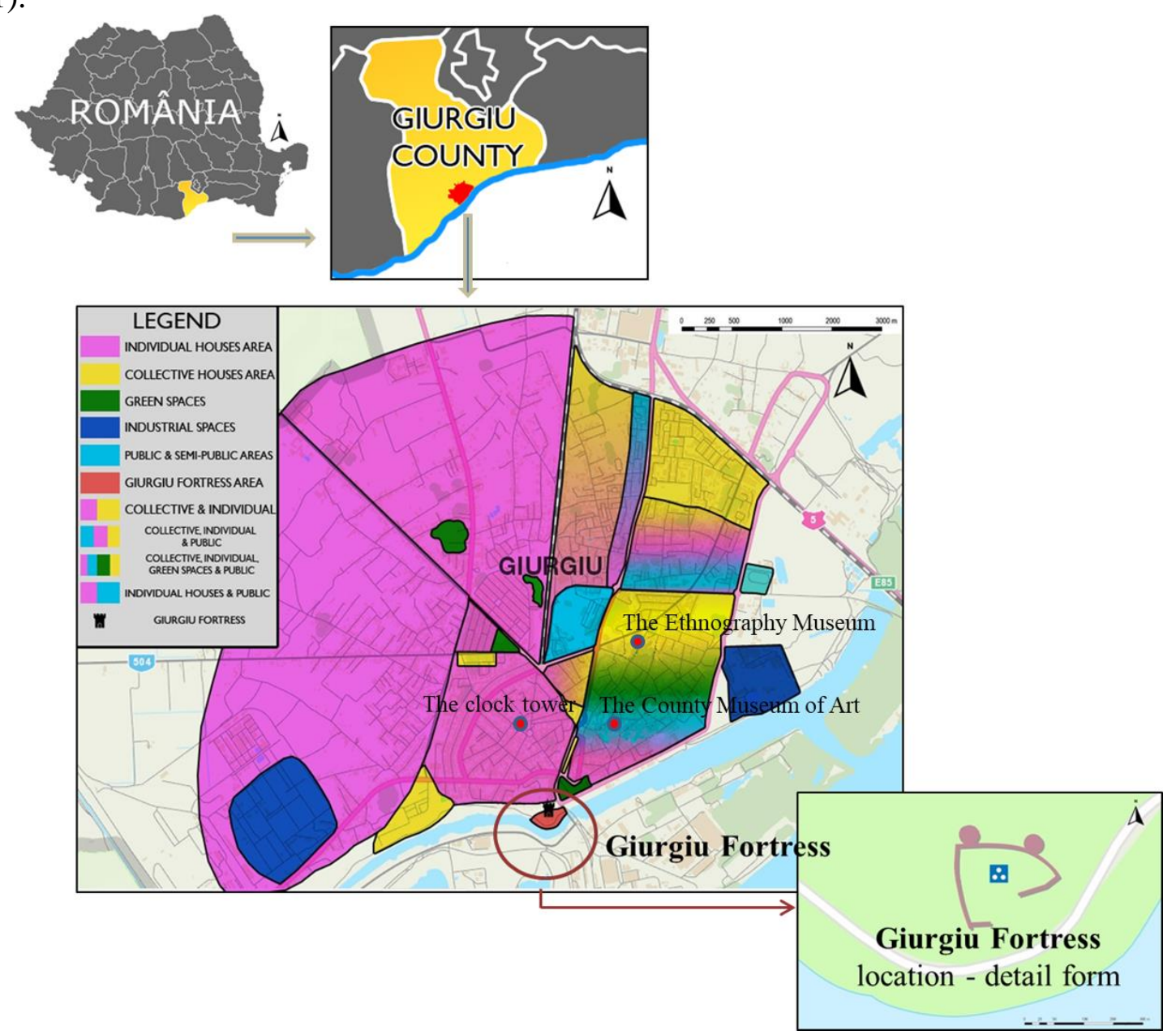

Figure 1. The functional structure of the city of Giurgiu and the location of the Fortress of Giurgiu within the city of Giurgiu, in Giurgiu County, Romania 
In order to obtain a clear answer, the questionnaire comprises four distinct parts:

a. personal data - for tracking the age segment which proves interest in capitalizing ruiniform heritage for tourist purpose and to analyze the positive or negative reactions depending on the age;

b. contextual variability - appreciation and consumption of cultural-tourist or heritage services;

c. knowledge of the details related to the ruiniform heritage or the resident's knowledge of the neighborhood heritage monument;

d. Involving the residents in arranging the heritage monument for the purpose of tourism valorization.

At the same time, on the city level, each area was identified, creating thus a picture of its functionality. In order to carry out a detailed analysis of the Fortress of Giurgiu, it is necessary to locate it in relation to the residential area of the city.

\section{RESULTS AND DISCUSSIONS}

a. Personal data - for tracking the age segment interested in capitalizing ruiniform heritage for tourist purpose and to analyze the positive or negative reactions depending on age (figure 2), socio-professional structure (figure 3) and level of education (figure 4). From the age point of view, the population of Giurgiu city is facing problems related to the demographic aging and a migratory balance from which there strikes clearly the movement of the predominantly young population towards the big cities of Romania, especially Bucharest, which is located at a rather small distance, or to the countries of the European Union. Thus, the residents participating in the study are mostly elderly, over 65 years old.

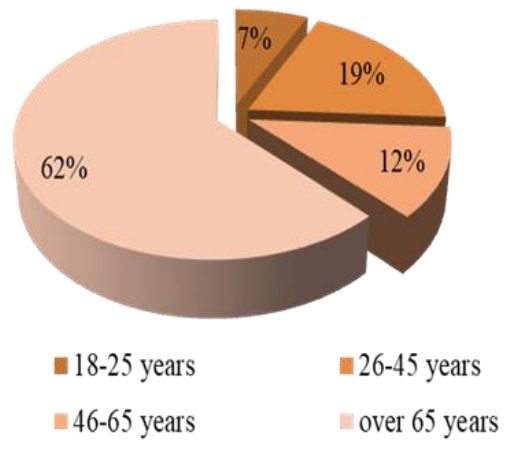

Figure 2. Age structure of the residents participating in the study

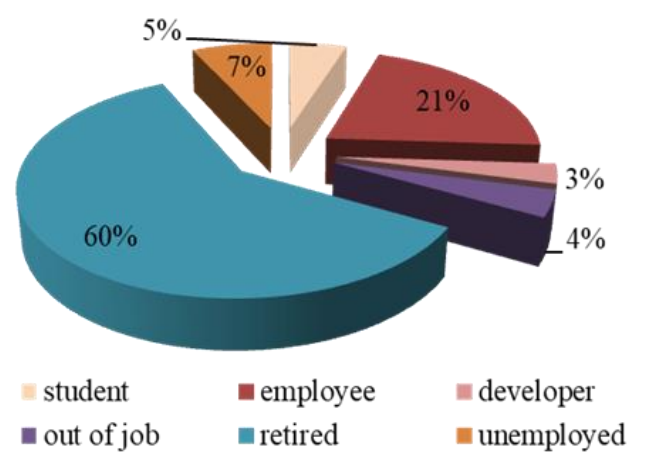

Figure 3. The socio-profesional structure of the residents participating in the study

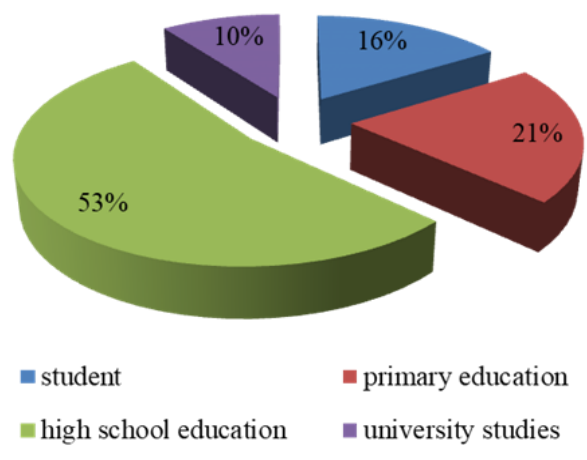

Figure 4. The educational structure of the residents participating in the study 
From a socio-professional point of view, the retired population ranks a significant percentage, to which there are added the employees, the unemployed and the other categories, in close percentages.

As level of education, most of the residents who participated in the study are high school graduates, followed by those who have a primary education. High school education is found among the population aged 18- 65 years, mostly and in a smaller percentile among the population over 65 years. Among them, most are with primary education, while very few with university studies.

b. Contextual variability - the appreciation and consumption of cultural-tourist or heritage services is the second point followed in the present study (figure 5). Raising children in a family environment in which cultural tourism was a form of habitually consumed tourism, is beneficial to the development possibilities of this type of tourism in the area in which they live (figure 6). Familiarization with cultural tourism - in this case, ruiniform material, is an advantage (figure 7). Following the application of the questionnaire, the results confirm that most of the residents of Giurgiu city do not seem to be consumers of such tourism. The appreciation, in general, regarding the cultural heritage tourism is in a secondary position. Over half of those who participated in the study, did not have any cultural-tourist activity with their family (figure 5), and on the other hand, more than $60 \%$ of them expressed a clear option of not being consumers or visitors of such tourist objectives (figure 6).

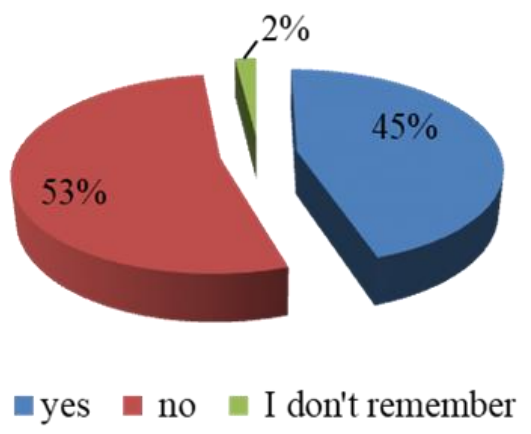

Figure 5. The degree of participation with the family when visiting the heritage monuments of those involved in the study

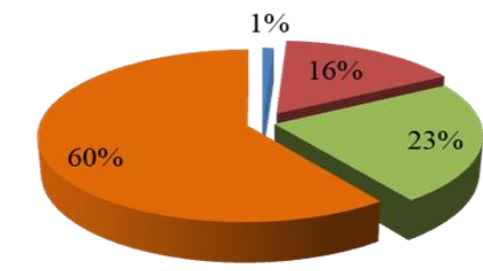

- several times a week a week

= how many times I have the opportunity

m every holiday or outing

m is not an attraction for me

Figure 6. Expression of the frequency of visiting the cultural monuments by the study participants

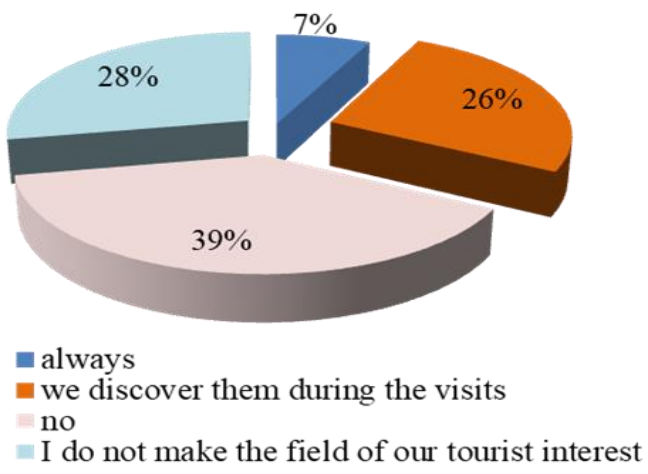

Figure 7. Individual training with information for visiting cultural monuments during vacations, as expressed by the study participants

But they are also a part of those who visit, generally historical and cultural monuments. Of the latter group, many stand for family visits in such places, both in cases of children, 
as well as adults who have become parents, they all stand for the cultural education of their children [14].

Regarding the preparation of a vacation, a visit or the theoretical discovery of the objectives to be seen during them, over $60 \%$ do not seem to be interested (figure 7 ). The percentage of the residents participating in the study, who are interested in the cultural values and the theoretical training related to the monuments to be visited, is below $10 \%$. Most are up to 45 years old, with high school and higher education. All these results create that picture of a society without interest for cultural values, and we make reference to both local, as well as to that part of society that could favor cultural tourism in general. Cultural education is formed in the family. School can also support it, while visits to art objecties and culturally milestone objectives can help the young generation develop attraction for this type of values. In turn, they can influence, through the education they receive, the family they form afterwards.

c. Knowing the historical data related to the ruiniform heritage or the residents' knowledge of the neighboring heritage monument -The Fortress of Giurgiu

Starting from the idea of developing and sustaining a cultural heritage tourism based on the ruins of the Fortress of Giurgiu, the results obtained from the residents participating in the study, the share of those who know the history of the city and of the city in general, is very low. They are, from educational point of view, with higher education and high school graduation and, they visit these ruins weekly, several times a month, never missing from any important events (figure 9). These are the only ones who consider that the Fortress of Giurgiu is a symbol of the city (figure 8). The history of the place is discovered and, it is learned through the repeated visits organized by the school together with the local officials. They could be considered the engine of local education [14]. The development of the society must be considered from the youngest ages. The respect for what each locality owns, must be cultivated and learned, which must also happen in the city of Giurgiu, a city - harbor on the Danube River, with a population that does not seem to be interested in, nor attracted by culture, or cultural heritage.

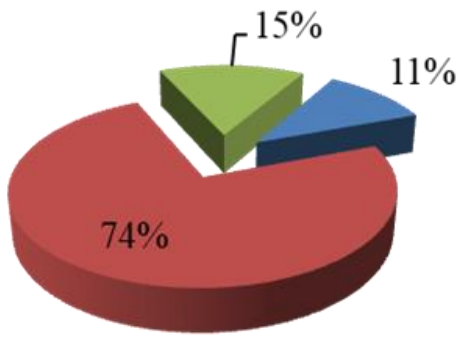

घes $\|$ no $=$ I don't know

Figure 8. The Fortress of Giurgiu-considered a symbol of the city for residents

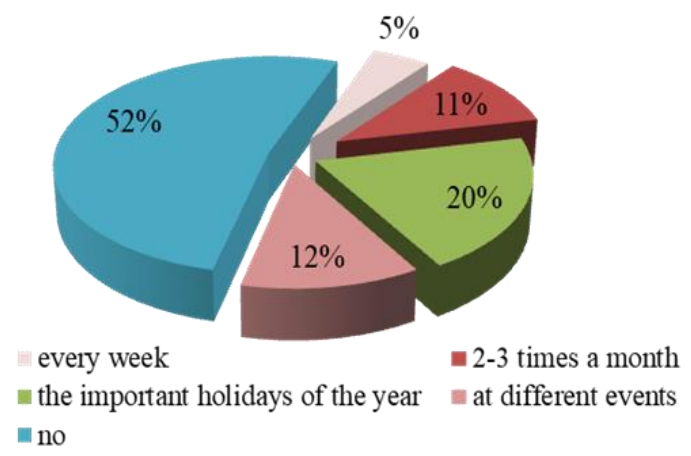

Figure 9. The visiting frequency of the Giurgiu Fortress, as stated by the residents participating in the study

d. Involving the residents in arranging the heritage monument for the purpose of tourism recovery

The lack of knowledge, or the ignorance and disinterest in the cultural heritage of a certain geographical area leads to the deterioration of the existing monuments. Their rehabilitation and transformation into tourist objectives can only be done with the help of 
the local population. If the residents are not interested, most of the time they can be a hindrance or, more often, they can ease the destruction of the monuments.

The placement of responsibility is not a real form of recognition of the value of a monument. The resident population in the city of Giurgiu is undoubtedly modest in material terms, and we could even say constrained, in terms of income. Involvement or intention, the desire to get involved in the development of a monument, anyway, is an activity that does not require funds. Of those who participated in the study, only $1 \%$ would be directly involved, working in the cleaning of the area of the Fortress of Giurgiu, or in providing information to those interested, or in making information panels (figure 10). Unfortunately, most do not consider it as an activity that may be of any interest for them as inhabitants, but rather something that falls within the responsibility of the local authorities.

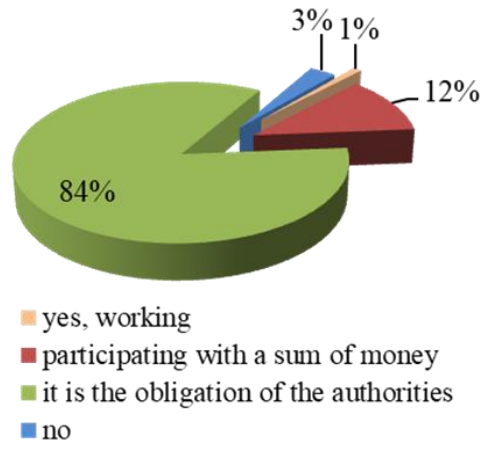

Figure 10. Involving residents and how to get involved in the arrangement and maintenance of the ruined heritage monuments analyzed

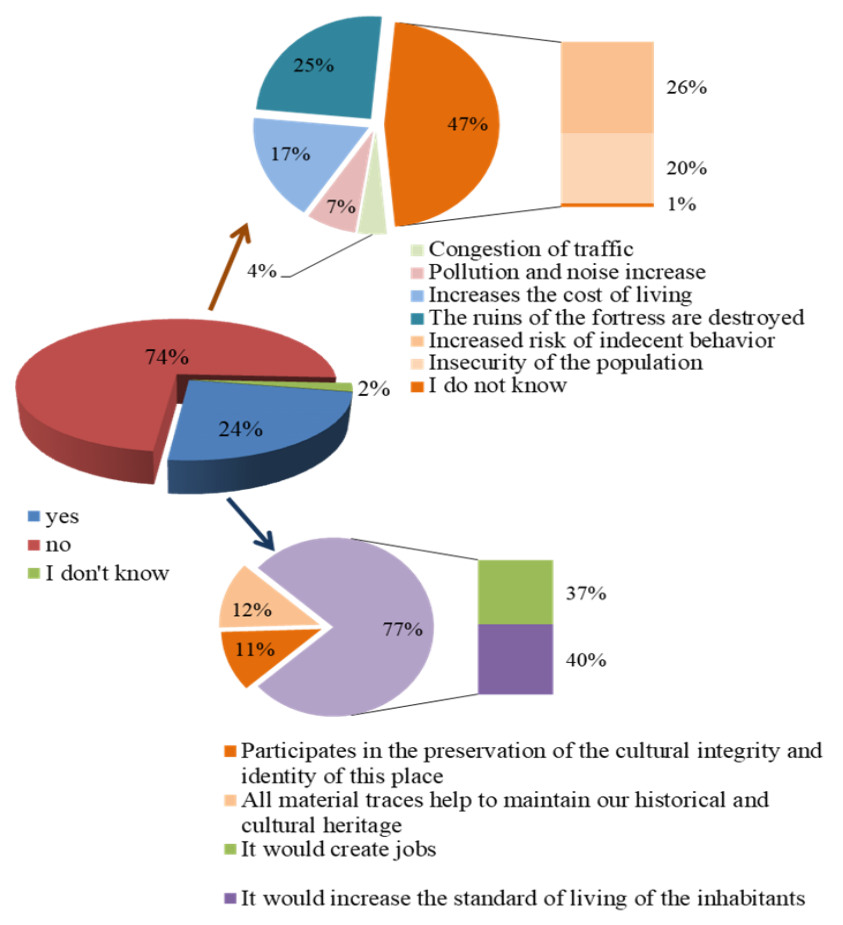

Figure 11. The positive and negative effects of the tourism axploatation of the Giurgiu Fortress for residents

This attitude does not support the tourist activity. Tourism is an economic activity with the particularities of involving the residents. Hospitality is one of these features. Tourists, regardless of their area of origin or age, come into contact with the locals. Their rejection or, the refusal of communication, the poor development of the road infrastructure, with tourist information and specific food, represent each a minus in the tourist attraction. The existence of the bridge connecting Bulgaria - Giurgiu - Ruse is a plus offered to the tourism development possibilities in this city.

The fortress itself can be a tourist attraction. In trying to find an explanation regarding the possibility of developing heritage tourism in this city, most residents, among those participating in the study, regarded tourism as a negative activity (figure 11).

The percentage of those who consider tourism to be negative is very high. Almost half of them consider that it could promote indecent behavior and increase the insecurity of the 
resident population. Just as many supporters of the negative effect that tourism can have are those who consider that by valorizing the ruins from touristic point of view, the ruins could be much more destroyed or, the cost of living would rise automatically.

Of the $24 \%$ who believe that tourism could have beneficial effects, most refer to its economic effects. Creating jobs and income earned by residents. These malfunctions regarding the use of tourism resources are present in other places [12]. Residents can have a point of view with major implications.

\section{CONCLUSIONS}

The present study starts from the idea that the relationship between tourism and residents is more than necessary. A sustainable economic activity must start from the premise that it brings a quality increase in the lives of the inhabitants. In this case, in the city of Giurgiu in Romania, a harbour city on the Danube, almost two millennia old, the historical heritage represented by the Fortress of Giurgiului could represent a real source of income. The study starts from the idea of necessarily consulting the residents regarding the development of cultural tourism in their city, especially of cultural tourism based on ruiniform heritage, of the fortress. The resident population is an aging population, and the economy of the locality is in a visible decline. Many of the economic units that functioned during the communist period, based on a centralized economy, are today ruins. The workforce is in a situation not quite pleasant, nor secure. In this case, on this socioeconomic background, the idea of developing tourism in a harbour- city loaded with history, is an important plus. The existence of a prosperous economy 30-35 ye/ars ago could lead to the idea of cultural perception of the residents. The residents participating in the study, especially those over 65, are those who reject the idea of capitalizing on this ruiniform material cultural heritage. On the other hand, regardless of age, they are not empathic, nor feel self- identified with these ruins as part of the local heritage. Both young and old people are modest in a fairly high percentage in the knowledge of the history of these monuments, but to a limited extent, some of them try to have an opening towards the social-economic side, that of capitalization, of the support that these monuments should benefit, as well as in finding the resources needed to be used, having that hope for jobs and secure incomes from a local activity.

ruiniform material cultural heritage, based on the certainty of supporting the residential population. It is a market study for what cultural urban tourism means. In this case, the The study brings as a novelty, a possible attempt to implement urban tourism based on the preservation of the ruins of the Fortress of Giurgiului would be the economic and social response, until the resident population realizes the importance of the values of the local culture. The study brings as a novelty, a possible attempt to implement urban tourism based on the ruiniform material cultural heritage, based on the certainty of supporting the residential population. It is a market study for what urban cultural tourism means. In this case, the preservation of the ruins of the Fortress of Giurgiului would be the economic and social response, until the resident population realizes the importance of the values of the local culture.

\section{REFERENCES}

[1] Barrera-Fernandez D. \& Hernandez-Escampa M., The impact of urban policy in the management of the tourist-historic city: a comparative study, Pasos-Revista de Turismo y Patrimonio Cultural, vol. 14, Issue 3, pp 705-724, 2016 
[2] Besculides, A., Lee, M.E. \& McCormick, P.J., Residents' Perception of the Cultural Benefits of Tourism, Annals of Tourism Research, Vol. 29, No. 2, pp 303-319, 2002

[3] Costa Hilário, Ana Catarina \& Marreiro das Chagas, Márcio, Influencia del escultismo en la formación personal y social de los scouts por medio de la práctica del turismo ecológico y pedagógico, Estudios y Perspectivas en Turismo, vol. 23, Issue 3, pp 484-50, 2014

[4] Dincă Iulian \& Camelia Teodorescu, The Romanian rural space and its landscapes: attraction and motivation for relocating townspeople, Geographia Napocensis, vol. 1, pp 21-36, 2015

[5] Gursoy, D., Jurowski, C. \& Uysal, M., Resident Attitudes: A Structural Modeling Approach, Annals of Tourism Research, vol. 29, No. 1, pp 79-105, 2002

[6] Herman G.V. \& Varnav R., Design elements for promoting attraction case study: Tara Oasului museum (Satu Mare County), Geojournal of tourism and geosites, vol. 14, Issue 2, Oradea, Romania, pp 168-177, 2014

[7] Hocaoglu D.A., The Role of Design in Cultural Heritage Based City Branding of Beypazari, Milli Folklor, vol. 109, pp 217-232, 2016

[8] Ilieș D.C., Baias Ș., Buhaș R., Ilies A., Herman G.V., Gaceu O., Dumbrava R. \& Măduța F.M., Environmental education in protected areas. Case study from Bihor county, Romania, Geojournal of tourism and geosites, vol. 19, Issue 1, pp 126-132, 2017

[9] Muresan, I.C., Oroian, C.E., Harun, R., Arion, F., Porutiu, A., Chiciudean, G., Todea, A. \& Lile, R., Local Residents' Attitude Toward Sustainable Rural Tourism development, Sustainability, Vol. 8, pp 2-14, 2016

[10] Noel Biseko Lwoga, Heritage proximity, attitudes to tourism impacts and residents' support for heritage tourism in Kaole Site, Tanzania, Bulletin of Geography. Socio-economic Series, No. 42, pp 163-181, 2018

[11] Pintilii Radu-Daniel, Daniel Peptenatu, Ana-Maria Ciobotaru, Sorin George Toma, Ana Maria Grigore, Cristian-Constantin Drăghici, Răzvan-Cătălin Dobrea, Adrian Gabriel Simion, Ion Andronache, Camelia Teodorescu \& Daniel Constantin Diaconu, Creative economies in Romania-spatial projections and trends, Bulletin of Geography. Socio-economic Series, Poland, vol. 37, pp 95-108, 2017.

[12] Teodorescu Camelia, Daniel Diaconu \& Roxana Radu, Disfunctionalities in the Organization and Development of SPA Tourism Developed on Salt Resources in Maramures, Romania, Public Recreation and Landscape Protection, vol. 1, pp 101-105, 2019

[13] Teodorescu Camelia, Octavian Teodorescu, Nicoleta Bira, Badea Alin \& Badea Livia Florina, Religious and cultural tourism and the socio-economic and educational implications, Quaestus Multidisciplinary Research Journal, Romania, vol. 8, pp 227-285, 2016

[14] Teodorescu Camelia, Radu-Daniel Pintilii, Peptenatu Daniel, Teodorescu Octavian \& Toma Sorin George, Popularizing Cultural Identity Through Religious Tourism-Socio-Economic and Educational Implications, International Multidisciplinary Scientific GeoConference: SGEM: Surveying Geology \& mining Ecology Management, Bulgaria, vol.3, pp 947-954, 2016

[15]Teodorescu Camelia, Vanturache Radu, Teodorescu Octavian \& Diaconu Constantin Daniel, Proposal for functional conversion - Bucharest Faur, Urbanism. Arhitectura. Constructii, Romania, vol. 7, pp 137-146, 2016.

[16] Torre, A. \& Rallet, A., Proximity and Localization, Regional Studies, vol. 39, No. 1, pp 47 59,2005

[17] Twining-Ward, L. \& Butler, R., Implementing STD on a Small Island: Development and Use of Sustainable Tourism Development Indicators in Samoa, Journal of Sustainable Tourism, vol. 10, pp 363- 387, 2002 